\title{
Prevalence of halitosis and related factors in North Indian population- A hospital based cross-sectional study
}

\author{
Akhilanand Chaurasia ${ }^{1, *}$, Gaurav Katheriya ${ }^{2}$ \\ ${ }^{1}$ Assistant Professor, ${ }^{2}$ Resident, Dept. of Oral Medicine and Radiology, Faculty of Dental Sciences, King George's Medical \\ University, Lucknow, Uttar Pradesh, India
}

*Corresponding Author:

Email: chaurasiaakhilanand49@gmail.com

\begin{abstract}
Objective: The Halitosis is also known as 'bad breath'. It is a symptom in which a noticeably unpleasant odour is present in the breath. This study is conducted to evaluate the age and sex related prevalence of halitosis, perception of halitosis, smoking and halitosis.

Materials and Method: A total of 1045 patients were screened from OPD of Department of Oral Medicine and Radiology. Out of all patients, 353 were male and 692 were female. Organoleptic scoring system was used to detect the grade of halitosis. Complete dental checkup of the patients were performed to find out the possible cause of malodor.

Results: The perception of halitosis is co-related with age groups and it was found that majority of study subjects were perceiving halitosis in each age group however the association of perceiving halitosis with age groups was statistically non significant(p>0.05).Majority of study subjects were perceiving halitosis in males and females. However this association was also statistically non-significant $(\mathrm{p}>0.05)$. However there was no significant association between perceiving halitosis with age groups for smoking status $(p>0.05)$. No signicant $(\mathrm{p}>0.05)$ association is found between perceiving halitosis with gender for smoking status (smokers and non smokers).

Conclusion: Halitosis is major health problem In India. The timely diagnosis and intervention by specialists, professional therapy, plaque control methods, education and awareness by professionals can help in prevention and management of Halitosis.
\end{abstract}

Keywords: Dental plaque, Tongue coating, Bad breath, Prevalence.

\section{Introduction}

Unpleasant odour emitted from an individual's oral cavity is referred to as halitosis. The other common terminologies that are used to denote halitosis are fetor oris, oral malodor, or bad breath. Halitosis is an oral health condition characterized by consistently emanating odorous breath and may be caused by several agents including poor oral hygiene, improper cleaning of dentures, decreased salivary flow rate, use of tobacco in any form or certain systemic conditions. ${ }^{1}$

Humans emit a variety of volatile and non-volatile molecules that are influenced by genetics, diet, stress and disease. The term 'Halitosis' is derived from the Latin word 'halitus' which means a complaint analogous to body odor ${ }^{2}$ and is used to describe any disagreeable odour in the breath. It's aetiology could be attributed to both intraoral or extra oral factors. However intra-oral reasons contribute about $90 \%$ of the cases being deep carious lesions, periodontal disease, peri implant disease, mucosal ulcers, food debris, reduced salivary flow rates or tongue coating. ${ }^{3}$ Among the listed intra oral causes for halitosis, tongue coating is the most common reason in otherwise healthy individuals with the odor arising from the dorsoposterior aspect of the tongue. ${ }^{4}$ The main compounds that lead to bad breath emanating from the oral cavity are the volatile sulfide compounds especially hydrogen sulfide, methyl mercapta and dimethylsulfide. ${ }^{5}$ These compounds are produced by the anaerobic gram negative microorganisms such as Treponema denticola,
Porphyromonas gingivalis, Porphyromonas endodontalis, Prevotella intermedia, Bacteroides loescheii, Enterobacteriaceae, Tannerella forsythensis, Centipeda periodontii, Eikenella corrodens and Fusobacterium nucleatum that inhabit the oral cavity. ${ }^{6}$ The microorganisms interact with the sulphur containing substances that are present in saliva, gingival crevicular fluid, blood and cells leading to the production of odiferous products. ${ }^{7}$

The number of epidemiological researches on halitosis is limited probably because of the difference in cultural and racial appreciation of the bad breath as for patients as well as for investigators and also because there is no uniformity in evaluation methods and diagnosis. ${ }^{8}$ Owing to different methodologies, the prevalence of halitosis is unclear and there are only a few community based studies evaluating the prevalence. ${ }^{9}$ However extensive studies on halitosis are necessary because it can be considered as a factor that influences the quality of life of patients which is preventable as oral hygiene is considered as responsible. $^{10}$

Halitosis frequently causes embarrassment, impaired interpersonal social communication ${ }^{11}$ and has also become an important market for the pharmacological and cosmetic. Oral malodor may rank behind only dental caries and periodontal disease as the reason for patients visiting the dentist. The perception of halitosis being different in culturally diverse populations. ${ }^{12}$ The true prevalence of halitosis is 
unknown and some reports are difficult to evaluate unless they specify the classification, terminology and methodology used. Currently available epidemiological data are difficult to evaluate as they are mainly based on subjective self-estimation of malodor which is well known to be limited by inaccuracy and low sensitivity.

However the available evidence suggests that halitosis is common and can affect people of all age groups. The prevalence of persistent oral malodor in a recent Brazilian study was reported to be $15 \%$, was nearly three times higher in men than in women (regardless of age) and the risk was slightly more than three times higher in people over 20 years of age compared with those aged 20 years or under controlling for gender. ${ }^{12}$ The large majority of studies report that about $30 \%$ of people have halitosis ${ }^{13-15}$ but some studies estimate that more than $50 \%$ of the population have halitosis. ${ }^{16}$ The precise prevalence of halitosis is still uncertain ${ }^{17}$ due to limited number of studies and even lesser number of studies with large samples..$^{18}$ It could also be due to the difficulty in evaluating some studies available that have no specification on classification, diagnosis or methodology used. ${ }^{17}$ The prevalence of halitosis according to the studies published is between $2 \%$ and $44 \%$ and this disparity is justified by the subjectivity of the diagnostic criteria, assessment methods and sampling techniques. ${ }^{19}$ Although the prevalence of halitosis has been studied in various populations in different parts of the world, different assessments and cut off points were presented. Therefore a precise estimate of the prevalence of halitosis is not possible to obtain. ${ }^{20}$

Many young adults complain of halitosis. It is estimated that $30 \%$ of the world population suffers with this problem regularly. ${ }^{21} \mathrm{~A}$ study ${ }^{22}$ conducted in a group of 2672 Japanese workers showed a prevalence of $14 \%$ of halitosis in the morning, $23 \%$ in the late morning, $6 \%$ in the afternoon and $16 \%$ at night. An observational study $^{23}$ conducted in a sample of 99 volunteers measured halitosis with gas chromatography and found a prevalence of $49 \%$. A French study ${ }^{24}$ showed about $22 \%$ of self reported halitosis. According to another study $^{25}$ nearly more than $50 \%$ of the general population has halitosis. In a Swedish ${ }^{26}$ study conducted in 840 men halitosis was reported to be around $2 \%$ of the population. Studies based on a questionnaire of 1551 subjects in Kuwait $^{27}$ reported $23 \%$ and 254 healthy elderly subjects ${ }^{28}$ reported $28 \%$ prevalence of halitosis in study population. Another study ${ }^{29}$ with 1052 subjects in Italy showed 19\% of self reported halitosis. Our study reports the prevalence rate of halitosis in males and females in north Indian population.

\section{Materials and Method}

All the study subjects enrolled for study were asked to sign the informed consent form for the study designed. Nature of study was explained to the patients. A total of 1045 subjects were selected from the OPD of
Department of Oral Medicine and Radiology. Out of all 1045 subjects, 353 were male and 692 were female. The study subjects who have undergone periodontal therapy, any systemic disease and female patients who are pregnant and lactating were excluded from the study. Organoleptic score were recorded for detection of the halitosis (Table 1).

Table 1: Grading of halitosis according to severity

\begin{tabular}{|c|l|c|}
\hline S. No. & \multicolumn{1}{|c|}{ Rating } & Intensity \\
\hline 1. & No halitosis & Grade 0 \\
\hline 2 & Barely noticeable odour & Grade 1 \\
\hline 3 & Slight odour & Grade 2 \\
\hline 4 & Moderate odour & Grade 3 \\
\hline 5 & Strong offensive & Grade 4 \\
\hline 6 & Extremely offensive & Grade 5 \\
\hline
\end{tabular}

Oral hygiene index taken for detection of debris and calculus (Green and Vermilion), Periodontal status was checked by Extent and Severity index (Carlos JP, Wolf MD). Complete dental checkup of the study subjects were performed to find out the possible cause of malodor. Presence of gingivitis and periodontitis, tongue coating, presence or absence of suppuration, deep caries, pericoronitis, brushing frequency and tobacco habit was noted.

\section{Statistical tools}

Categorical variables will be presented in number and percentage (\%). Qualitative variables will be compared using Chi-Square test /Fisher's exact test as appropriate. A p value of $<0.05$ will be considered statistically significant. The data is entered in MS Excel spreadsheet and analysis will be done using Statistical Package for Social Sciences (SPSS) version 21.0.

\section{Results}

A total 1045 study subjects has been screened for halitosis. The minimum age of study subjects were 15 years with a maximum age of 79 years (Table 1). Out of 1045 study subjects 353 were male $(33.8 \%)$ and $692(66.2 \%)$ were females (Table 2). The perception of Halitosis is co-related with age groups and it was found that majority of study subjects were perceiving halitosis in each age group however the association of perceiving halitosis with age groups was statistically non significant $(p>0.05)$ (Table 3). The perception of Halitosis is compared with sex of study subjects. It was found that majority of study subjects were perceiving halitosis in male and females group of study population (Table 4). However this association was also statistically non-significant( $p>0.05)$. Table 5 shows association of age groups and perceiving halitosis status according to their smoking status (smoker vs nonsmoker). It shows that majority of the study subjects were perceiving halitosis in smokers than non-smokers irrespective of age groups (Table 5). However there was no significant association between perceiving 
halitosis with age groups for smoking status $(p>0.05)$. The association of gender and perceiving halitosis status according to their smoking status (smoker vs nonsmoker) is studied in the population. It was found that majority of study subjects perceiving halitosis were smokers in both male and female group. However no signicant $(p>0.05)$ association is found between perceiving halitosis with gender for smoking status (smokers and non smokers) (Table 6).

Table 1: Showing the mean age in study population

\begin{tabular}{|c|c|c|c|c|c|}
\hline & N & Minimum & Maximum & Mean & $\begin{array}{c}\text { Std. } \\
\text { Deviation }\end{array}$ \\
\hline Age & 1045 & 15.00 & 79.00 & 48.0679 & 15.38024 \\
\hline
\end{tabular}

Table 2: Showing the sex wise distribution of study population

\begin{tabular}{|c|c|c|}
\hline Gender & Frequency & Percent \\
\hline Male & 353 & 33.8 \\
\hline Female & 692 & 66.2 \\
\hline Total & 1045 & 100.0 \\
\hline
\end{tabular}

Table 3: Showing the prevalence of Halitosis in age groups

\begin{tabular}{|c|c|c|c|c|c|c|}
\hline $\begin{array}{c}\text { Perceiving } \\
\text { Halitosis }\end{array}$ & \multicolumn{5}{|c|}{ Age intervals } & Total \\
\hline & $\begin{array}{c}\text { Below } \\
18 \mathrm{yr}\end{array}$ & $\begin{array}{c}18 \text { to } \\
35 \mathrm{yr}\end{array}$ & $\begin{array}{c}36 \text { to } \\
50 \mathrm{yrs}\end{array}$ & $\begin{array}{c}51 \text { to } \\
65 \mathrm{yrs}\end{array}$ & $\begin{array}{c}\text { Above } \\
65 \mathrm{yrs}\end{array}$ & \\
\hline \multirow{2}{*}{ Yes } & 16 & 177 & 236 & 235 & 101 & 765 \\
\cline { 2 - 7 } & $88.9 \%$ & $78.0 \%$ & $71.3 \%$ & $72.8 \%$ & $69.2 \%$ & $73.2 \%$ \\
\hline \multirow{2}{*}{ No } & 2 & 50 & 95 & 88 & 45 & 280 \\
\cline { 2 - 7 } & $11.1 \%$ & $22.0 \%$ & $28.7 \%$ & $27.2 \%$ & $30.8 \%$ & $26.8 \%$ \\
\hline \multirow{2}{*}{ Total } & 18 & 227 & 331 & 323 & 146 & 1045 \\
\cline { 2 - 7 } & $100.0 \%$ & $100.0 \%$ & $100.0 \%$ & $100.0 \%$ & $100.0 \%$ & $100.0 \%$ \\
\hline
\end{tabular}

Table 4: Showing the prevalence of Halitosis in Male and Female of study population

\begin{tabular}{|c|c|l|c|c|c|}
\hline \multirow{3}{*}{$\begin{array}{c}\text { Perceiving } \\
\text { Halitosis }\end{array}$} & & & \multicolumn{2}{|c|}{ Gender } & \\
\cline { 2 - 6 } & \multirow{3}{*}{ Yes } & Count & Male & Female & Total \\
\cline { 3 - 6 } & & $\%$ within Gender & $74.2 \%$ & $72.7 \%$ & $73.2 \%$ \\
\cline { 2 - 5 } & \multirow{2}{*}{ No } & Count & 91 & 189 & 280 \\
\cline { 3 - 6 } & & $\%$ within Gender & $25.8 \%$ & $27.3 \%$ & $26.8 \%$ \\
\hline \multicolumn{2}{|c|}{ Total } & Count & 353 & 692 & 1045 \\
\cline { 3 - 6 } & \% within Gender & $100.0 \%$ & $100.0 \%$ & $100.0 \%$ \\
\hline
\end{tabular}

Table 5: Showing the relation between age groups, smoking habit and Halitosis

\begin{tabular}{|c|c|c|c|c|c|c|}
\hline \multicolumn{3}{|c|}{ Age Intervals } & \multicolumn{2}{|c|}{ Smoking Status } & \multirow[t]{2}{*}{ Total } & \multirow[t]{2}{*}{ P value } \\
\hline & & & Present & Absent & & \\
\hline \multirow[t]{6}{*}{ Below 18yr } & \multirow{4}{*}{$\begin{array}{c}\text { Perceiving } \\
\text { Halitosis }\end{array}$} & Yes & & 16 & 16 & \multirow{4}{*}{ NA } \\
\hline & & & & $88.9 \%$ & $88.9 \%$ & \\
\hline & & \multirow[t]{2}{*}{ No } & & 2 & 2 & \\
\hline & & & & $11.1 \%$ & $11.1 \%$ & \\
\hline & \multirow{2}{*}{\multicolumn{2}{|c|}{ Total }} & & 18 & 18 & \\
\hline & & & & $100.0 \%$ & $100.0 \%$ & \\
\hline \multirow[t]{6}{*}{18 to $35 \mathrm{yr}$} & \multirow{4}{*}{$\begin{array}{c}\text { Perceiving } \\
\text { Halitosis }\end{array}$} & \multirow[t]{2}{*}{ Yes } & 18 & 159 & 177 & \multirow{4}{*}{.277} \\
\hline & & & $85.7 \%$ & $77.2 \%$ & $78.0 \%$ & \\
\hline & & \multirow[t]{2}{*}{ No } & 3 & 47 & 50 & \\
\hline & & & $14.3 \%$ & $22.8 \%$ & $22.0 \%$ & \\
\hline & \multirow{2}{*}{\multicolumn{2}{|c|}{ Total }} & 21 & 206 & 227 & \\
\hline & & & $100.0 \%$ & $100.0 \%$ & $100.0 \%$ & \\
\hline \multirow[t]{2}{*}{36 to $50 y r s$} & \multirow{2}{*}{$\begin{array}{c}\text { Perceiving } \\
\text { Halitosis }\end{array}$} & \multirow[t]{2}{*}{ Yes } & 40 & 196 & 236 & \multirow{2}{*}{.125} \\
\hline & & & $64.5 \%$ & $72.9 \%$ & $71.3 \%$ & \\
\hline
\end{tabular}




\begin{tabular}{|c|c|c|c|c|c|c|}
\hline & & \multirow[t]{2}{*}{ No } & 22 & 73 & 95 & \\
\hline & & & $35.5 \%$ & $27.1 \%$ & $28.7 \%$ & \\
\hline & \multirow{2}{*}{\multicolumn{2}{|c|}{ Total }} & 62 & 269 & 331 & \\
\hline & & & $100.0 \%$ & $100.0 \%$ & $100.0 \%$ & \\
\hline \multirow[t]{6}{*}{51 to $65 \mathrm{yrs}$} & \multirow{4}{*}{$\begin{array}{l}\text { Perceiving } \\
\text { Halitosis }\end{array}$} & Yes & 59 & 176 & 235 & \multirow{4}{*}{.387} \\
\hline & & & $74.7 \%$ & $72.1 \%$ & $72.8 \%$ & \\
\hline & & No & 20 & 68 & 88 & \\
\hline & & & $25.3 \%$ & $27.9 \%$ & $27.2 \%$ & \\
\hline & \multirow{2}{*}{\multicolumn{2}{|c|}{ Total }} & 79 & 244 & 323 & \\
\hline & & & $100.0 \%$ & $100.0 \%$ & $100.0 \%$ & \\
\hline \multirow[t]{6}{*}{ Above $65 \mathrm{yrs}$} & \multirow{4}{*}{$\begin{array}{l}\text { Perceiving } \\
\text { Halitosis }\end{array}$} & Yes & 33 & 68 & 101 & \multirow{4}{*}{.506} \\
\hline & & & $70.2 \%$ & $68.7 \%$ & $69.2 \%$ & \\
\hline & & \multirow[t]{2}{*}{ No } & 14 & 31 & 45 & \\
\hline & & & $29.8 \%$ & $31.3 \%$ & $30.8 \%$ & \\
\hline & \multirow{2}{*}{\multicolumn{2}{|c|}{ Total }} & 47 & 99 & 146 & \\
\hline & & & $100.0 \%$ & $100.0 \%$ & $100.0 \%$ & \\
\hline
\end{tabular}

Table 6: Showing the relation between gender, smoking habits and Halitosis

\begin{tabular}{|c|c|c|c|c|c|c|}
\hline \multirow{2}{*}{\multicolumn{3}{|c|}{ Gender }} & \multicolumn{2}{|c|}{ Smoking Status } & \multirow[t]{2}{*}{ Total } & \multirow[t]{2}{*}{$P$ value } \\
\hline & & & Present & Absent & & \\
\hline \multirow[t]{6}{*}{ Male } & \multirow{4}{*}{$\begin{array}{c}\text { Perceiving } \\
\text { Halitosis }\end{array}$} & \multirow[t]{2}{*}{ Yes } & 141 & 121 & 262 & \multirow[t]{4}{*}{.165} \\
\hline & & & $71.9 \%$ & $77.1 \%$ & $74.2 \%$ & \\
\hline & & \multirow[t]{2}{*}{ No } & 55 & 36 & 91 & \\
\hline & & & $28.1 \%$ & $22.9 \%$ & $25.8 \%$ & \\
\hline & \multirow{2}{*}{\multicolumn{2}{|c|}{ Total }} & 196 & 157 & 353 & \\
\hline & & & $100.0 \%$ & $100.0 \%$ & $100.0 \%$ & \\
\hline \multirow[t]{6}{*}{ Female } & \multirow{4}{*}{$\begin{array}{c}\text { Perceiving } \\
\text { Halitosis }\end{array}$} & Yes & 9 & 494 & 503 & \multirow[t]{4}{*}{.494} \\
\hline & & & $69.2 \%$ & $72.8 \%$ & $72.7 \%$ & \\
\hline & & \multirow[t]{2}{*}{ No } & 4 & 185 & 189 & \\
\hline & & & $30.8 \%$ & $27.2 \%$ & $27.3 \%$ & \\
\hline & \multirow{2}{*}{\multicolumn{2}{|c|}{ Total }} & 13 & 679 & 692 & \\
\hline & & & $100.0 \%$ & $100.0 \%$ & $100.0 \%$ & \\
\hline
\end{tabular}

\section{Discussion}

The major aim of this cross-sectional study was to predispose the enlightenment and related determinants of halitosis in the patients coming in our OPD. Since oral malodor is an olfactory stimulus direct smelling of the exhaled air by judges is considered the most logical measurement approach. ${ }^{30}$ The prevalence of halitosis has been studied in different populations all over the world with a variety of techniques and cut-offs but the prevalence of halitosis is still not well established. Most of the prevalence studies are based on self perceived breath odor and do not correlate well with other halitosis measurements. ${ }^{31}$ Bornstein et $\mathrm{al}^{32}$ stated that $32 \%$ of Swiss adults reported experiencing halitosis sometimes or often $(\mathrm{N}=419)$. Setia et $\mathrm{al}^{33}$ reported that $45 \%$ of Indian dental students $(\mathrm{N}=277)$ reported halitosis, with $>80 \%$ of them experiencing morning bad breath.

Zürcher et $\mathrm{al}^{34}$ investigated that the prevalence of halitosis in the general Dutch population $(\mathrm{N}=1,002,>16$ years old), and reported that almost $90 \%$ of the population was regularly faced with a person having halitosis, $40 \%$ at least once a week.
Miyazaki et $\mathrm{al}^{35}$ with the help of VSC (Halimeter) reported that prevalence of moderate halitosis is $(\geq 75$ $\mathrm{ppb})=28 \%$.

Loesche et $\mathrm{a}^{36}$ stated that prevalence of self perception was $31 \%$ and prevalence of halitosis informed by others was $24 \%$. Frexinos et al ${ }^{37}$ stated that prevalence of self-reported halitosis was $22 \%$.Söder et $\mathrm{al}^{38}$ reported using organoleptic that prevalence of severe halitosis was $2.4 \%$. Nalçaci et $\mathrm{al}^{39}$ investigated using organoleptic that prevalence of halitosis was $14.5 \%$. Saito et $\mathrm{al}^{40}$ interviewed 33,427 persons $\$ 15$ years of age from all regions of Japan, and reported $14.5 \%$ problems with oral malodor. Hence this showed that the halitosis was the most important oral health concern for $70 \%$ of the questioned businessmen from Tokyo.

Liu et $\mathrm{al}^{41}$ found a higher prevalence in women only in the age group of 35-44 years old.

Miyazaki et $\mathrm{al}^{35}$ and Nadanovsky et $\mathrm{al}^{42}$ stated that there was some association between halitosis and progression of age. on the other hand in our study we observed that majority of the patients were higher in perceiving halitosis present patients in all age groups 
There was no significant association between age intervals with their perceiving halitosis ( $p>0.05)$.

The association of gender of patients and their perceiving halitosis shows that majority of the patients were higher in perceiving halitosis and in both males and females. There was no significant association between gender with their perceiving halitosis $(\mathrm{p}>0.05)$. The association of age groups and perceiving halitosis status according to their smoking status (smoker verses non smoker) showed that majority of the patients were higher in perceiving halitosis and present in smokers. There was no significant association between perceiving halitosis with age groups for smoking status (p>0.05).

So it was concluded that halitosis is boundless in the study population and is escorted by a low level of consciousness. Tongue coating and smoking are significantly associated with halitosis. Only Tooth brushing is not effective in solving this problem so tongue brushing should be part of daily oral hygiene and should be included in the oral hygiene instructions given to patients and the public. Health care providers including dentists and clinician should pay more attention to health education regarding halitosis since halitosis from an extra-oral origin can be the sign of an underlying systemic disease. The treatment of patients with halitosis should be performed according to a standardized scheme. Patients with extra-oral halitosis and halitophobia must be referred to appropriate specialists such as an otorhinolaryngologist, internist, psychologist, or psychiatrist.

\section{Conclusion}

Halitosis is an oral health condition characterized by consistently emanating odorous breath and may be caused by several agents including poor oral hygiene, improper cleaning of dentures, decreased salivary flow rate, use of tobacco in any form, or certain systemic conditions. Halitosis is major health problem In India. The timely diagnosis and intervention by specialist, professional therapy and plaque control methods and education and awareness by professionals can help in prevention and management of halitosis.

\section{References}

1. Cortelli JR, Barbosa MD, Westphal MA. Halitosis: A review of associated factors and therapeutic approach. Braz Oral Res 2008;22(Suppl 1):44-54.

2. Lee SS, Zhang W, Li Y. Halitosis update: a review of causes, diagnoses, and treatments. J Calif Dent Assoc 2007:262:264-8.

3. van den Broek AM, Feenstra L, de Baat C. A review of the current literature on management of halitosis. Oral Dis 2008;14:30-9.

4. Yaegaki K, Sanada K. Volatile sulfur compounds in mouth air from clinically healthy subjects and patients with periodontal disease. J Periodontal Res 1992;27:2338.
5. Tonzetich J. Production and origin of oral malodor: A review of mechanisms and methods of analysis. $J$ Periodontol 1977;48:13-20.

6. Awano S, Gohara K, Kurihara E, Ansai T, Takehara T. The relationship between the presence of periodontopathogenic bacteria in saliva and halitosis. Int Dent J 2002;52:212-6.

7. Quirynen M, Zhao H, Soers C, Dekeyser C, Pauwels M, Coucke W, et al. The impact of periodontal therapy and the adjunctive effect of antiseptics on breath odorrelated outcome variables: A doubleblind randomized study. $J$ Periodontol 2005;76:705-12.

8. Bollen CM, Beikler T. Halitosis: the multidisciplinary approach. Int J Oral Sci 2012 Jun;4(2):5563.

9. YoungnakPiboonratanakit P, Vachirarojpisan T. Prevalence of selfperceived halitosis in a group of Thai dental patients. J Dent (Tehran) 2010 Sep;7(4):196-204.

10. Domingos PAS, Abreu AC, Dantas AAR, Oliveira ALBM. Halitosis: limiting the quality of life. Rev de Odont Univ Cid de São Paulo 2011 May-Aug;23(2):171-81.

11. Bosy A. Oral malodor: philosophical and practical aspects. J Can Dent Assoc 1997:63:196-201.

12. Nadanovsky P, Carvalho LB, Ponce de Leon A. Oral malodour and its association with age and sex in a general population in Brazil. Oral Dis 2007:13:105-9.

13. Liu XN, Shinada K, Chen XC, Zhang BX, Yaegaki K, Kawaguchi Y. Oral malodor-related parameters in the Chinese general population. J Clin Periodontol 2006:33: 31-6.

14. Outhouse TL, Al-Alawi R, Fedorowicz Z, Keenan JV. Tongue scraping for treating halitosis. Cochrane Database Syst Rev 2006:19;(2):CD005519.

15. Sanz M, Rolda'n S, Herrera D. Fundamentals of breath malodour. J Contemp Dent Pract 2001:4:1-17.

16. Tessier JF, Kulkarni GV. Bad breath: etiology, diagnosis and treatment. Oral Health 1991:81:19-22.

17. Scully C, Greenman J. Halitosis (breath odor). Periodontol 2000 2008;486-675.

18. Van den Broek AM, Feenstra L, de Baat C. A review of the current literature on aetiology and measurement methods of halitosis. J Dent 2007 ;35(8):62735.

19. Sanz M, Roldán S, Herrera D. Fundamentals of breath malodour. J Contemp Dent Pract 2001 Nov;2(4):117.

20. Rosing CK, Loesche W. Halitosis: an overview of epidemiology, etiology and clinical management. Braz. Oral Res 2011 Sep-Oct;25(5):46671.

21. Tonzetich J, Kestenbaum RC. Halitosis: a review of mechanisms and methods of analysis. J Periodontol 1977 Jan;48(1):1320.

22. Miyazaki H, Sakao S, Katoh Y, Takehara T. Correlation between volatile sulphur compounds and certain oral health measurements in the general population. $J$ Periodontol 1995;66(8):67984.

23. Nunes JC, Oliveira L, Martínez Sahuquillo A. Halitose: estudo de prevalência e factores de riscoassociadosnumaUnidade de Saúde Familiar. Rev Port Med Geral Fam 2012;283449. in Portuguese.

24. Frexinos J, Denis P, Allemand H, Allouche S, Los F, Bonnelye G. Descriptive study of digestive functional symptoms in the French general population. Gastroenterol Clin Biol 1998 Oct;22(10):78591.

25. Nachnani S. Halitosis: causes, assessment, and treatment. Compend Contin Educ Dent 2011 Jan-Feb;32(1):224.

26. Soder B, Johansson B, Soder PO. The relation between foetor ex ore, oral hygiene and periodontal disease. Swed Dent J 2000;24(3):7382.

27. AlAnsari JM, Boodai H, AlSumait N, AlKhabbaz AK, AlShammari KF, Salako N. Factors associated with self 
reported halitosis in Kuwaiti patients. J Dent 2006 Aug;34(7):4449.

28. Nalcaci R, Baran I. Factors associated with selfreportedhalitesis (SRH) and perceived taste disturbance (PTD) in elderly. Arch Gerontol Geriatr 2008 May-Jun;46(3):30716.

29. Settineri S, Mento C, Gugliotta SC, Saitta A, Terranova A, Trimarchi G. Self-reported halitosis and emotional state: impact on oral conditions and treatments. Health Qual Life Outcomes 2010 Mar;834.

30. Hammad MM, Darwazeh AM, Al-Waeli H, Tarakji B, Alhadithy TT. Prevalence and awareness of halitosis in a sample of Jordanian population. J Int. Society of Preventive \& Com Dent 2014 Dec;4(Suppl 3):S178.

31. Miyazaki H, Sakao S, Katoh Y, Takehara T. Correlation between volatile sulphur compounds and certain oral health measurements in the general population. $J$ Periodontol 1995;66:679-84.

32. Bornstein MM, Kislig K, Hoti BB, Seemann R, Lussi A.Prevalence of halitosis in the population of the city of Bern,Switzerland: a study comparing self-reported and clinical data. Eur J Oral Sci 2009;117:261-7.

33. Setia S, Pannu P, Gambhir RS, Galhotra V, Ahluwalia P, Sofat A.Correlation of oral hygiene practices, smoking and oral health conditions with self perceived halitosis amongst undergraduate dental students. J Nat Sci Biol Med 2014;5:67-72.

34. Zürcher A, Laine ML, Filippi A. Diagnosis, prevalence, and treatment of halitosis. Current Oral Health Reports 2014 Dec 1;1(4):279-85.

35. Miyazaki H, Sakao S, Katoh Y, Takehara T. Correlation between volatile sulphur compounds and certain oral health measurements in the general population. $J$ Periodontol 1995 Aug;66(8):679-84.

36. Loesche WJ, Grossman N, Dominguez L, Schork MA. Oral malodour in the elderly. In: van Steenberghe D, Rosenberg M, editors. Bad breath: a multidisciplinary approach. Leuven: Leuven University Press; 1996:18194.

37. Frexinos J, Denis P, Allemand H, Allouche S, Los F, Bonnelye G. [Descriptive study of digestive functional symptoms in the French general population]. Gastroenterol Clin Biol 1998 Oct;22(10):785-91. French.

38. Söder B, Johansson B, Söder PO. The relation between foetor exore, oral hygiene and periodontal disease. Swed Dent J 2000 Mar;24(3):73-82.

39. Nalçaci R, Dülgergil T, Oba AA, Gelgör IE. Prevalence of breath malodour in 7-11-year-old children living in Middle Anatolia, Turkey. Com Dent Health 2008 Sep;25(3):173-7.

40. Saito H, Kawaguchi Y. Halitosis prevention campaign.A report of oral health promotion activities in Japan. Int Dent J 2002;52:197-200.

41. Liu XN, Shinada K, Chen XC, Zhang BX, Yaegaki K, Kawaguchi Y. Oral malodor-related parameters in the Chinese general population. J Clin Periodontol 2006;33:31-6.

42. Nadanovsky P, Carvalho LB, Ponce de Leon A. Oral malodour and its association with age and sex in a general population in Brazil. Oral Dis 2007;13:105-9. 